\title{
Genotyping of human parvovirus B19 in clinical samples from Brazil and Paraguay using heteroduplex mobility assay, single-stranded conformation polymorphism and nucleotide sequencing
}

\author{
Marcos César Lima de Mendonça ${ }^{1}$, Ana Maria de Amorim Ferreira ${ }^{2}$, \\ Marta Gonçalves Matos dos Santos², Elva Cristina Oviedo ${ }^{3}$, Maria Sônia Dal Bello ${ }^{4}$, \\ Marilda Mendonça Siqueira ${ }^{5}$, Juan Manuel Piñeiro Maceira ${ }^{6}$, \\ Maria Genoveva von Hubinger ${ }^{2}$, José Nelson dos Santos Silva Couceiro²/+

\begin{abstract}
${ }^{1}$ Campus Macaé ${ }^{2}$ Departamento de Virologia, Instituto de Microbiologia Prof. Paulo de Góes, Centro de Ciências da Saúde ${ }^{6}$ Serviço de Anatomia Patológica, Hospital Universitário Clementino Fraga Filho, Universidade Federal do Rio de Janeiro, Rio de Janeiro, RJ, Brasil ${ }^{3}$ Laboratorio Central de Salud Pública, Ministerio de Salud Pública, Asunción, Paraguay ${ }^{4}$ Faculdade de Medicina, Universidade de Passo Fundo, Passo Fundo, RS, Brasil

${ }^{5}$ Laboratório de Vírus Respiratórios e Sarampo, Instituto Oswaldo Cruz-Fiocruz, Rio de Janeiro, RJ, Brasil
\end{abstract}

Heteroduplex mobility assay, single-stranded conformation polymorphism and nucleotide sequencing were utilised to genotype human parvovirus B19 samples from Brazil and Paraguay. Ninety-seven serum samples were collected from individuals presenting with abortion or erythema infectiosum, arthropathies, severe anaemia and transient aplastic crisis; two additional skin samples were collected by biopsy. After the procedure, all clinical samples were classified as genotype 1 .

Key words: parvovirus B19 - nucleotide sequencing - genotyping - HMA - SSCP

Human erythroviruses are more commonly known as parvovirus B19 (B19V). They belong to the Erythrovirus genus within the Parvovirinae subfamily and the Parvoviridae family (Fauquet et al. 2005). The B19V are responsible for a wide range of human diseases such as erythema infectiosum (fifth disease), transient aplastic anaemia and hydrops fetalis, as well as arthropathy in adults, chronic anaemia in immunocompromised patients and abortion (Feder \& Anderson 1989, Kirchner 1994).

Based on the phylogenetic analysis of the B19V DNA sequences, it was proposed that B19V should be classified into three distinct genotypes: B19V-related viruses corresponding to genotype 1 (prototype strain Au), A6related viruses corresponding to genotype 2 (prototype strains LaLi and A6) and V9-related viruses corresponding to genotype 3 (prototype strains V9 and D 91.1) (Servant et al. 2002).

To determine which genotypes of B19V are present in some geographic Brazilian and Paraguayan regions, clinical samples were analysed by single-stranded conformation polymorphism (SSCP), heteroduplex mobility assay (HMA) and nucleotide sequencing. HMA and SSCP have been widely employed for DNA mapping, identification and genotyping (Hayashi \& Yandell 1993, Barlow et al. 2000) because they reduce the number of samples that require analysis by nucleotide sequencing (Mendonça et al. 2008).

Financial support: CNPq, CAPES, FAPERJ, FINEP, FUJB/UFRJ

+ Corresponding author: jncouceiro@micro.ufrj.br

Received 24 September 2010

Accepted 4 May 2011
In this work, 99 polymerase chain reactions (PCR)positive samples for B19V were utilised. Ninety-seven serum samples were collected from individuals presenting with abortion (2) or with clinical symptoms such as exanthema (47), arthropathies (4), severe anaemia (2) or transient aplastic crisis (2). Two samples were collected by skin biopsy from injuries not related to B19V. Additional samples (40) originated from patients presenting with exanthematic diseases who had tested positive for $\mathrm{B} 19 \mathrm{~V}$ via the enzyme-linked immunosorbent assay (ELI$\mathrm{SA}$ ) test, but negative for measles and rubella viruses. All samples were supplied by Brazilian (LACEN-RJ-Laboratório Central de Saúde Pública Noel Nutels, Fundação Oswaldo Cruz, HEMORIO-Instituto Estadual de Hematologia Arthur de Siqueira Cavalcanti, Hospital Universitário Clementino Fraga Filho (HUCFF) and Hemocentro Regional de Passo Fundo) and Paraguayan (Laboratorio Central de Salud Pública) public institutions.

The samples were collected from individuals from Southern, South-eastern and Midwestern Brazil and also from Paraguay. The majority of samples were collected between August-December in the years 1997 through 2005. The clinical samples were identified by their geographic region of origin followed by a number: Paraguay (PAR), Goiás (GO) (Midwestern Region, Brazil), Rio de Janeiro (RJ) (South-eastern Region, Brazil) and Rio Grande do Sul (RS) (Southern Region, Brazil). The project was approved by the Ethics Committee of HUCFF of the Universidade Federal do Rio de Janeiro (Brazil). All experiments were performed in compliance with relevant laws and institutional guidelines and in accordance with the Declaration of Helsinki.

Two different adapted protocols were utilised for DNA extraction from serum and formalin-fixed skin samples, as already preconised (Cassinotti et al. 1993, 
Mendonça et al. 2008). DNA from the genotypes 1, 2 and 3 of B19V prototypes were used as standard samples: (i) prototype strain Au (GenBank M13178) and T900 (clinical sample) (Mendonça et al. 2008) of the genotype 1, (ii) variant A6 (GenBank AY064476) of the genotype 2 and (iii) variant Gh3051 (GenBank AY582125) of the genotype 3. The semi-nested PCR, which was performed in two steps, amplified a partial VP1-unique region of $327 \mathrm{bp}$. In the first PCR, primers PVP1 (ACAAGCCTGGGCAAGTTAGC) and PVP2 (CTGCACCAGTGCTGGCTTCT) were used; in the second PCR, PVP3 (TGGGCCTGGCAATGAGCTAC) and PVP2 were utilised, as reported previously (Mendonça et al. 2008).

In SSCP analysis, $10 \mu \mathrm{L}$ of PCR product were mixed with $6 \mu \mathrm{L}$ of formamide buffer at $95 \%$ including $20 \mathrm{mM}$ EDTA and $0.25 \%$ bromophenol blue dye, heated to $95^{\circ} \mathrm{C}$ for $5 \mathrm{~min}$, and immediately transferred to ice for $2 \mathrm{~min}$ until gel application. The reaction was then applied to a $15 \%$ polyacrylamide gel in Tris- $\mathrm{HCl}$ buffer, $\mathrm{pH} 6.8$ and subjected to electrophoresis at $60 \mathrm{~V}$ for $18 \mathrm{~h}$ at $4^{\circ} \mathrm{C}$. The sample was visualised by silver staining (Herring et al. 1982, Mendonça et al. 2008). In HMA analysis, each set of two samples was compared by mixing together $3.5 \mu \mathrm{L}$ of each PCR product. The mixture was heated to $98^{\circ} \mathrm{C}$ for $5 \mathrm{~min}$ and $55^{\circ} \mathrm{C}$ for $30 \mathrm{~min}$ and was then maintained at $25^{\circ} \mathrm{C}$ until gel application. Electrophoresis was performed utilising a $15 \%$ polyacrylamide gel in Tris- $\mathrm{HCl}$ buffer, $\mathrm{pH} 8.8$, at $30 \mathrm{~V}$ for $17 \mathrm{~h}$ at room temperature. The sample was visualised by silver staining (Mendonça et al. 2008). A subset of our samples was selected to represent each SSCP or HMA electrophoretic pattern (CP5/GenBank HQ127222, PAR89/GenBank HQ127220, RJ7/GenBank HQ127221, RJ802/GenBank HQ127218, RJ11/GenBank HQ127219, PAR100/GenBank HQ127216, GO864/GenBank HQ127215, RS816/ GenBank HQ127217 and RJ886/GenBank HQ127214). They were sequenced in the forward and reverse directions using primers PVP3 and PVP2, respectively, as already reported (Mendonça et al. 2008).

From SSCP analysis, 58 samples (represented by RJ808) presented the same pattern as prototype $\mathrm{Au}, 29$ (represented by RJ220) presented the same as T900 (clinical sample of genotype 1) (Mendonça et al. 2008) and eight samples presented their own individual patterns (Fig. 1). Another five samples could not be tested by SSCP due to insufficient sample and the lack of extracted DNA. The HMA analysis showed that 95 samples presented homoduplexes against genotype 1 and heteroduplexes when tested against genotypes 2 and 3. Another four samples (RJ802, RS816, GO864 and RJ11) presented heteroduplexes when tested against any genotype (Fig. 2).

The crossover among HMA and SSCP results revealed that all 58 SSCP Au-like samples and all 29 SSCP T900-like samples, such as PAR89, RJ7, PAR100 and RJ886 samples, presented homoduplexes against genotype 1 . However, it was not possible to determine the genotypes of RJ802, RS816, GO864 and RJ11. These samples presented heteroduplexes against genotypes 1 and 2, while RJ802, RS816, GO864 and RJ11 presented heteroduplexes against genotypes 1,2 and 3. To confirm the results from SSCP and HMA analyses, two SSCP
Au-like samples (RJ2011 and RJ866) and two SSCP T900-like samples (T900 and RJ771), besides PAR89, RJ7, RJ802, RJ11, PAR100, GO864, RS816 and RJ886 samples, were submitted to nucleotide sequencing. After the alignment and phylogenetic analysis (data not shown), all samples were classified as genotype 1 . The SSCP Au-like and T900-like groups were detected in all regions studied, including Paraguay and the Brazilian states of Espírito Santo, Minas Gerais, RJ, RS and GO.

After nucleotide sequencing, it was shown that the SSCP Au-like samples have the same nucleotide sequence as the Au prototype, while the T900-like samples present only one substitution point (synonymous substitution) when they are compared to Au (Mendonça et al. 2008). The eight samples with their own pattern presented two or three substitutions when compared to Au.

Variations up to one nucleotide ( $99.7 \%$ of similarity) could be detected by SSCP and confirmed by nucleotide sequencing. Thus, PAR89 and RJ7 samples that exhibited sequence variations of only one nucleotide and a very similar SSCP standard could be distinguished due to a small delay in migration (Fig. 1).

The pattern distribution exhibited no significant differences in relation to symptoms, sex or year and month of incidence. However, in previous Brazilian studies, all three genotypes were detected (Sanabani et al. 2006, Keller et al. 2009). These studies utilised samples collected from individuals who had haematological symptoms or who were infected with human deficiency virus;

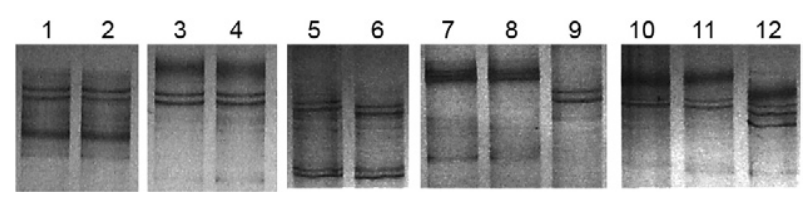

Fig. 1: single-stranded conformation polymorphism analysis of the mobility shift of denatured single-stranded DNA fragments in parvovirus B19 standard* and clinical samples. The clinical samples were identified by their geographic region of origin followed by a number: Paraguay (PAR), Goiás (GO) (Midwestern Region, Brazil), Rio de Janeiro (RJ) (South-eastern Region, Brazil) and Rio Grande do Sul (RS) (Southern Region, Brazil). Lane 1: Au genotype 1*; 2: RJ808; 3: T900* (clinical sample of genotype 1) (Mendonça et al. 2008); 4: RJ220; 5: PAR89; 6: RJ7; 7: RJ802; 8: RJ11; 9: RJ886; 10: PAR100; 11: GO864; 12: RS816.

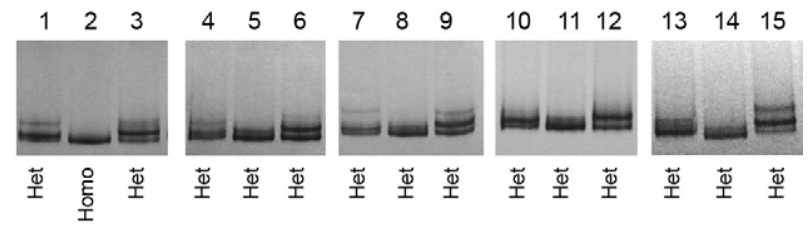

Fig. 2: heteroduplex mobility assay analysis of the mobility shift heteroduplex formations (Het) in mixtures of set of different parvovirus B19 clinical samples and Au genotype 1 (G1), A6 genotype 2 (G2) and Gh3051 genotype 3 (G3) parvovirus B19 standard samples. Lane 1: G2+RJ2011; 2: G1+RJ2011; 3: G3+RJ2011; 4: G2+RJ802; 5: G1+RJ802; 6: G3+RJ802; 7: G2+RS816; 8: G1+RS816; 9: G3+RS816; 10: G2+RJ11; 11: G1+RJ11; 12: G3+RJ11; 13: G2+GO864; 14: G1+GO864; 15: G3+GO864. Homo: homoduplex formations. 
most of our samples originated from patients with exanthematic symptoms. However, Freitas et al. (2008) identified genotypes 1 and 3 as being responsible for exanthematic infections in habitants from the Brazilian Amazon Region, showing significant predominance of genotype 1 (91\%) and evidence of dissemination of genotype 3.

At the moment, genotype 1 is the most commonly detected genotype in the world, but genotype 3 has been observed in many countries as well (Hübschen et al. 2009). This work shows the presence of B19V genotype 1 in Southeast, South and Midwestern Regions of Brazil through 2005, but continuous monitoring is necessary to detect all known genotypes and the emergence of new genotypes of these viruses.

\section{ACKNOWLEDGEMENTS}

To Dayse Ferreira (Fiocruz), for the screening of serum anti-parvovirus IgM by ELISA.

\section{REFERENCES}

Barlow K, Green J, Clewley J 2000. Viral genome characterization by the heteroduplex mobility and heteroduplex tracking assays. Rev Med Virol 10: 321-335.

Cassinotti P, Weitz M, Siegl G 1993. Human parvovirus B19 infections: routine diagnosis by a new nested polymerase chain reaction assay. J Med Virol 40: 228-234.

Fauquet CM, Mayi MA, Maniloff J, Desselberger U, Ball L 2005. Virus taxonomy, 8th Report of the ICTV, Elsevier/Academic Press, London, 1259 pp.

Feder Jr, HM Anderson I 1989. Fifth disease: a brief review of infections in childhood, in adulthood and in pregnancy. Arch Intern Med 149: 2176-2179.

Freitas RB, Melo FL, Oliveira DS, Romano CM, Freitas MR, Macêdo O, Linhares AC, de A Zanotto PM, Durigon EL 2008. Molecular characterization of human erythrovirus B19 strains obtained from patients with several clinical presentations in the Amazon Region of Brazil. J Clin Virol 43: 60-65.

Hayashi K, Yandell DW 1993. How sensitive is PCR-SSCP? Human Mut 2: 338-346.

Herring AJ, Inglis NF, Ojeh CK, Snodgrass DR, Menzies JD 1982. Rapid diagnosis of rotavirus infection by direct detection of viral nucleic acid in silver-stained polyacrylamide gels. J Clin Microbiol 16: 473-477.

Hübschen JM, Mihneva Z, Mentis AF, Schneider F, Aboudy Y, Grossman Z, Rudich H, Kasymbekova K, Sarv I, Nedeljkovic J, Tahita MC, Tarnagda Z, Ouedraogo JB, Gerasimova AG, Moskaleva TN, Tikhonova NT, Chitadze N, Forbi JC, Faneye AO, Otegbayo JA, Charpentier E, Muller CP 2009. Phylogenetic analysis of human parvovirus b19 sequences from eleven different countries confirms the predominance of genotype 1 and suggests the spread of genotype 3b. J Clin Microbiol 47: 3735-3738.

Keller LW, Barbosa ML, Melo FL, Pereira LM, David-Neto E, Lanhez LE, Durigon EL 2009. Phylogenetic analysis of a near-fulllength sequence of an parvovirus B19 genotype 3 strain isolated in Brazil. Arch Virol 154: 1685-1687.

Kirchner JT 1994. Erythema infectiosum and other parvovirus B19 infections. Am Farm Phys 50: 335-342.

Mendonça MCL, Ferreira AMA, Santos MGM, Barros JJF, von Hubinger MG, Couceiro JNSS 2008. Heteroduplex mobility assay and single-stranded conformation polymorphism analysis as methodologies for detecting variants of human erythroviruses. J Virol Meth 148: 40-47.

Sanabani S, Kleine WN, Pereira J, Sabino EC 2006. Sequence variability of human parvovirus B19 present in bone marrow of Brazilian patients with various parvovirus B19-related hematological symptoms. J Clin Microbiol 44: 604-606.

Servant A, Laperche S, Lallemand F, Marinho V, De Saint Maur G, Meritet JF, Garbarg-Chenon A 2002. Genetic diversity within human erythroviruses: identification of three genotypes. $J$ Virol 76: 9124-9134. 